\title{
The influence of European legislation on the use of diagnostic test allergens for nasal allergen provocation in routine care of patients with allergic rhinitis*
}

\author{
L. Klimek', A.S. Hammerbacher ${ }^{2}$, P.W. Hellings ${ }^{3,4}$, W.J. Fokkens ${ }^{4}$, H.J. Hoffmann ${ }^{5}$, Do: 10.4193/Rhino14.316 \\ A. Muraro ${ }^{6}$, N. Papadopoulos ${ }^{7}$
}

*Received for publication: December 12, 2014

Accepted: February 11, 2015

${ }^{1}$ Center for Rhinology and Allergology, An den Quellen 10, D-65183 Wiesbaden, Germany

2 Regulatory Sciences Manager Bristol-Myers Squibb, Regulatory Sciences Germany, Arnulfstraße 29, D-80636 München, Germany

${ }^{3}$ Department of Otorhinolaryngology, University Hospitals Leuven, Kapucijnenvoer 33, B-3000 Leuven, Belgium

${ }^{4}$ Department of Otorhinolaryngology, Academic Medical Centre, Amsterdam, The Netherlands

${ }^{5}$ Chairman, Interest Group Allergy Diagnosis, EAACI, Department Respiratory Disease and Allergy, Institute of Clinical Medicine,

University of Aarhus, Aarhus C, Denmark

${ }^{6}$ Secretary General of the European Academy of Allergy and Clinical Immunology (EAACI); Head Food Allergy Referral Centre Veneto

Region, Department of Women and Child Health Padua General University Hospital, Padua, Italy

7 President European Academy of Allergy and Clinical Immunology (EAACI), Centre for Paediatrics and Child Health, Institute of

Human Development, University of Manchester, Royal Manchester Children's Hospital, Manchester, United Kingdom

\begin{abstract}
In patients with allergic rhinitis (AR), the nasal provocation test (NPT) is the standard procedure to evaluate the clinical response of the nasal mucosa to allergens with a high specificity and sensitivity. In AR, it is the only test that really measures the response of the diseased mucosa to allergens while skin prick test and serum lgE confirm the clinical suspicion of sensitization. Moreover, it is of special relevance in the detection of patients with Local Allergic Rhinitis (LAR), where general sensitization cannot be measured. For the evaluation of therapeutic interventions, NPT has been used for the clinical monitoring of antiallergic drugs and allergen specific immunotherapy.

Legislation within the European Union (EU) defines allergens used for diagnostic tests like NPT to be medicinal products according to Directive 2001/83 EC, but national law is considering these products to be medicinal devices in a number of EU countries. Thus, NPT products are governed by different legislations and therefore standards throughout the EU. In consequence, allergens used for diagnostic purposes need different registrations and Marketing Authorization by national authorities.

After a transition period, regulations of EU Directives are to be implemented in national law by all member states. At the moment, most EU countries have not fully implemented these Directives, however, it can be expected that most countries will implement it and enforce their rules within the next years. This development has a tremendous impact on the availability of diagnostic allergens for NPT in Europe and will make make nasal provocation testing very difficult if not impossible.

We describe the current situation of diagnostic allergens under the special legislative conditions in the EU with special focus on allergen products used for NPT and the consequences for the diagnosis of AR and LAR.
\end{abstract}

Key words: Nasal provocation testing, allergic rhinitis, diagnostic test allergens, allergen products, marketing authorization, local allergic rhinitis (LAR; EU Directive 2001/83)

\section{Introduction}

The Nasal provocation test (NPT) or nasal allergen challenge is an important diagnostic tool for routine testing of inhalational allergies. Kirkman in 1835 and Blackley in 1873 were the first to record the nasal response of hay fever patient towards sniffing pollen like sweet vernal grass pollen ${ }^{(1,2)}$. Blackley also tested responses to pollen by conjunctival and parabuccal instillation ${ }^{(2)}$. Since then, NPT is used to evaluate the clinical response of the 
nasal mucosa in patients with allergic rhinitis. NPT may be helpful in patients with polysensitization to ratify the allergic origin of the symptoms and to confirm the probable causative allergen (3). NPT can further be used to monitor the patient's response to medication or to allergen specific immunotherapy, quantitatively evaluating the nasal mucosal response during the course of treatment ${ }^{(4,5)}$. Sequentially escalating doses of allergen are administered in this regard to the nasal mucosa and the procedure is then called a titrated NPT.

Finally, in local allergic rhinitis (LAR) with unique production of specific IgE antibodies locally in the nasal mucosa, NPT seems to be the only useful diagnostic tool, as in this specific condition skin testing and serum specific lgE tests are not helpful ${ }^{(6,7)}$. Thus, NPT today is an established standard procedure that is helpful in several conditions and allows reproducing the clinical response of an allergen at the nasal mucosa with high specificity and sensitivity ${ }^{(4,8,9)}$.

However, to fulfill these conditions, NPT requires a broad spectrum of well standardized diagnostic test allergens of high quality.

\section{Allergens used for in vivo diagnosis of allergic diseases like in NPT are medicinal products in Europe}

Allergens used for diagnostic tests or therapy are defined as medicinal products (allergen products) since 1989 in the European Union (EU) according to the Council Directive of May 3rd, 1989 $(89 / 342 / E E C)^{(10)}$. In consequence, allergens used for diagnostic purposes like skin tests or provocation tests (later referred to as diagnostic Test Allergen:TA) become allergen products and thus need registration and authorization by national authorities within the EU. This is also true for allergens used to evaluate the clinical response of the nasal mucosa in NPT. In Article 6 this directive states: "Except as provided in paragraph 2, Member States shall take the necessary measures to comply with this Directive not later than 1 January 1992". Since then, the legal requirement for marketing authorization of TAs should be in effect in the EU. Currently, this process has not been completed in all EU Member states. However, this delay may shortly be caught, since new regulatory documents are currently in preparation, for example in Spain (Resolución Alergenos Borrador) as well as in Italy and Portugal.

The community code on human medicines, i.e. Directive 2001/83 EC and others define the implementation in human medicine within the EU. After a transition period, regulations of EU Directives are to be implemented in national law by all member states according to EU legislation rules.

When directives 2001/83 EC and 89/342/EEC were released, some allergen products on the market corresponded to individual preparations (Named Patient Products: NPPs). Thus, specific provisions have been introduced, enabling each Member state to individually decide on the conditions to market such preparations in its own country. However, diagnostic allergen products are not prepared specially for one individual, so they do not correspond to NNPs but they are "standard", industrially pre-manufactured medicinal products. Therefore, an important issue in this context is that possible exemptions from authorization as intended in Directive 2001/83 for NPPs are not applicable to TAs - both in skin tests and provocation tests.

This development as a whole has a tremendous impact on in vivo allergy diagnosis in Europe and especially on NPT, since it can be expected, that in the future every individual TA applied for nasal provocation tests in any EU Member state has to be authorized ${ }^{(11)}$.

\section{Development of European legislation for allergen products} An early important document to govern allergens within the framework of European legislation was Directive 89/342/EEC, which extended the scope of Directives 65/65/EEC and 75/319/ EEC and laid down additional provisions for immunological medicinal products (vaccines, toxins, sera and allergens) ${ }^{(10,12)}$. This directive defines allergen products as "... any product that is intended to identify or induce a specific acquired alteration in the immunological response to an allergizing agent". Therefore, both allergen products for diagnostic as well as for therapeutic use fell under the scope of this Directive and were clearly defined as medicinal products ${ }^{(12)}$.

This definition has been retained in Directive 2001/83/EC ${ }^{(13)}$, which applies to "all medicinal products [...] prepared industrially". The central requirement of Directive 2001/83/EC is stated in Article $6^{(12): ~ " N o ~ m e d i c i n a l ~ p r o d u c t ~ m a y ~ b e ~ p l a c e d ~ o n ~ t h e ~}$ market of a Member State unless a Marketing Authorization has been issued by the competent authorities of that Member State in accordance with this Directive [...]". Directive 2001/83/ EC was amended by EU Directive 2004/27/EC [12] that added „... allergen product which is manufactured employing an industrial process [....] or manufactured by a method involving an industrial process".

This Directive 2004/27/EC has introduced major changes for the allergen manufacturers. Previously, the Marketing Authorization (MA) was mandatory only for allergen products prepared industrially, meaning that individual preparations were not concerned. With Directive 2004/27/EC medicinal products either prepared industrially or manufactured by a method involving an industrial process have to be granted a MA before they can be placed on the market in the EU.

Again, this Directive laid down the regulatory framework for allergen products for therapeutic and also for diagnostic use. However, for therapeutic allergens, exceptions were made for therapy allergens, which are manufactured for an individual patient on the basis of an individual prescription to accommodate the special nature of allergen products intended for the treatment of rare allergies ${ }^{(12)}$. In this case, therapeutic allergens 
do not require a MA. But since TAs are not manufactured for an individual patient on the basis of an individual prescription, this exception does not apply for TAs.

Following release of the European directive 89/342, implementations in the local regulations of the Member states took place like e.g. in France with Law n 92-1279 of 8 December 1992 modifying the Public health code, in Italy with the decrees dated 29 May 1991 and 13 December 1991, in Spain with the royal decree 288/1991 dated 8 March 1991 and in Germany with the technical guide of $1992^{(12)}$.

Currently, the situation in Europe is very inhomogenous. Some EU member countries like Germany, UK and Poland have authorizations for diagnostic TAs in place, however, the authorization requirements are very different in these countries. Several other countries don't have authorized TA's on the market. Germany is the only EU Member state that requires a MA especially for TAs in NPT. The country registered the first allergen products for diagnostic use in 1985 and the first TAs for provocation tests in 1990. The German database of the Paul Ehrlich Institute (PEl: www.PEl.de) contained the following information at October 31, 2014 (Table 1): a total of 28 allergen products of Grass-/Cereal-/ Herbal pollen for provocation have been registered between 1990 and 2002, 24 allergen products for provocation with tree pollen have been registered between 1990 and 1991, 21 allergen products for provocation with mould and yeast allergens have been registered between 1990 and 2004, 9 allergen products for provocation with house dust mites and storage mites have been registered between 1991 and 2002 and 12 allergen products for provocation with Animal dander/ -epithelia, have been registered between 1990 and 1991.

In Spain and Italy, the regulatory process is still under construction, currently no licences are granted for diagnostic products. In the United Kingdom and The Netherlands, licenced allergen products are available for skin prick test, but not for NPT. In France, there is a specific regulatory framework for the Allergen Specially Prepared for one Individual (APSI) since 1959. The APSI authorisation granted to the two French allergen product manufacturers covers a total of 64 allergen substances that could be used for the further preparation of products for diagnostic use.

\section{Definitions}

According to the Guideline on allergen products ${ }^{(14)}$ an allergen is a molecule capable of inducing an IgE response and/ or a Type I allergic reaction, while allergen extracts are extracts from natural biological source materials containing a mixture of allergenic and non-allergenic molecules and allergen products are medicinal products containing allergens or derivatives of allergens for the purpose of in vivo diagnosis or treatment of allergic diseases.

Allergen extracts may be grouped in homologous groups based on the composition and the physiochemical as well as biological properties of the source material, the cross-reactivity/structural homology of allergens, the formulation of the finished product and the production process of the allergen extract and of the finished allergen product ${ }^{(14)}$. For group formation all four criteria have to be fulfilled ${ }^{(14)}$.

\section{Standardization of allergen extracts}

As allergen extracts are prepared from natural source material, they are complex mixtures of antigenic compounds and exhibit considerable biological variability ${ }^{(12)}$. Thus, standardization of the extraction process and hence the final product is of major importance and is a key issue for the quality and safety of allergen products ${ }^{(14)}$.

In Europe, most manufacturers employ the In-House Reference Preparation (IHRP) principle for the standardization of their products: each batch of the product is compared to a respective internal reference standard. The general monograph on allergen products of the European Pharmacopoeia ${ }^{(16)}$ and the Guideline on allergen products ${ }^{(17)}$ provide detailed guidance on how to characterize IHRPs and state specifications that allergen products have to comply with ${ }^{(12)}$. An allergen product should be characterized with respect to three major criteria, and these criteria should be standardized as much as possible ${ }^{(12,18)}$ :

- The total allergen composition should be determined to ensure that all major allergens are present in the product

- Allergens that are defined as relevant by the manufacturer should be measured to ensure that they are present in constant ratios in the product

- The total allergenic activity should be quantitated to determine the overall potency of the product.

Currently, the potency of allergen extracts can either be biologically standardized (e.g. skin testing) or by using in vitro techniques (IgE binding assays). For the biological standardization of allergen products, two different standardization systems are in use ${ }^{(12)}$ : the US-American approach ${ }^{(19)}$, which uses intradermal testing in 15 highly sensitized individuals, and the Scandinavian approach based on the Danish Allergen standardization Program from $1976^{(20)}$, which employs skin-prick tests on 20 moderate and highly sensitized individuals. Both methods are used throughout Europe for the standardization of allergen extracts and rely on the quantification of the skin reaction from which biological units are derived. Usually, manufacturers characterize their IHRPs with respect to the abovementioned criteria, set individually differing biological units and compare each batch of allergen product that is manufactured to the respective IHRP. This does allow for consistency and comparability between batches of one manufacturer but does not provide comparability of batches between different manufacturers ${ }^{(21)}$. IgE-inhibition tests are frequently used as in vitro standardization methods and are 
Table 1. Pollen of Grasses / Cereals / Herbals. Database of the Paul Ehrlich Institute (PEl: www.PEl.de) containing authorized test allergens for provocation tests in Germany (information from October 31, 2014).

\begin{tabular}{|c|c|c|c|}
\hline Test allergen & Allergen manufacturer & Authorization No & Date of Authorization \\
\hline Ambrosia (Ragweed) & HAL Allergie GmbH & 1310a/89Nb-1 & 01.04 .1990 \\
\hline Mugwort & Leti Pharma GmbH & PEI.D.02488.01.2 & 17.12.2002 \\
\hline Mugwort & Allergopharma GmbH \& Co. KG & $75 a / 87 b$ & 04.06.1991 \\
\hline Stinging nettle & Allergopharma GmbH \& Co. KG & $76 a / 87 b$ & 04.06.1991 \\
\hline Common Mugwort & HAL Allergie GmbH & $1307 a / 89 \mathrm{Nb}-1$ & 01.04 .1990 \\
\hline Common Mugwort & HAL Allergie GmbH & $1307 \mathrm{a} / 89 \mathrm{Nb}-2$ & 01.04 .1990 \\
\hline Barley & Allergopharma GmbH \& Co. KG & $418 a / 86 b$ & 04.06.1991 \\
\hline Cereal Mix & Leti Pharma GmbH & PEI.D.02512.01.2 & 17.12.2002 \\
\hline Pellitory & Leti Pharma GmbH & PEI.D.01592.02.2 & 17.12 .2002 \\
\hline Grasses & Allergopharma GmbH \& Co. KG & $387 a / 86 b$ & 04.06.1991 \\
\hline Grasses / Cereals & Allergopharma GmbH \& Co. KG & $439 a / 86 b$ & 04.06 .1991 \\
\hline Grass Mix & Leti Pharma GmbH & PEI.D.02513.01.2 & 17.12.2002 \\
\hline Grass Mix & HAL Allergie GmbH & $760 \mathrm{a} / 89 \mathrm{Nb}-1$ & 01.04 .1990 \\
\hline Herbals & Allergopharma GmbH \& Co. KG & $90 a / 87 b$ & 04.06.1991 \\
\hline Timothy & Leti Pharma GmbH & PEI.D.01554.02.2 & 17.12.2002 \\
\hline Dandelion & Allergopharma GmbH \& Co. KG & $83 a / 87 b$ & 04.06.1991 \\
\hline Nettle & HAL Allergie GmbH & $1304 \mathrm{a} / 89 \mathrm{Nb}$ & 01.04 .1990 \\
\hline Nettle & HAL Allergie GmbH & $1304 a / 89 \mathrm{Nb}-1$ & 01.04 .1990 \\
\hline Rye & HAL Allergie GmbH & 750a/89Nb-1 & 01.04 .1990 \\
\hline Rye & Allergopharma GmbH \& Co. KG & $427 a / 86 b$ & 04.06.1991 \\
\hline Common Sheep Sorrel & HAL Allergie GmbH & $1308 \mathrm{a} / 89 \mathrm{Nb}-1$ & 01.04 .1990 \\
\hline Short Ragweed & Allergopharma GmbH \& Co. KG & $86 a / 87 b$ & 04.06.1991 \\
\hline Summer Herbals Mix & HAL Allergie GmbH & $1317 \mathrm{a} / 89 \mathrm{Nb}-1$ & 01.04 .1990 \\
\hline Ribgrass & HAL Allergie GmbH & $1305 \mathrm{a} / 89 \mathrm{Nb}-1$ & 01.04 .1990 \\
\hline Plantain & Allergopharma GmbH \& Co. KG & $88 a / 87 b$ & 04.06.1991 \\
\hline Wheat & HAL Allergie GmbH & $755 a / 89 N b-1$ & 01.04 .1990 \\
\hline Wheat & Allergopharma GmbH \& Co. KG & $432 a / 86 b$ & 04.06.1991 \\
\hline Common Timothy & HAL Allergie GmbH & 753a/89Nb-1 & 01.04 .1990 \\
\hline
\end{tabular}

required in the EP monograph on allergen products as control for batch-to-batch consistency ${ }^{(12)}$. These tests however lack informations about the content of single allergens ${ }^{(18)}$.
Recombinant major allergens as certified reference materials and the respective ELISAs for the measurement of these major allergens in allergen products may advance standardization of 
Table 1. Tree Pollen.

\begin{tabular}{|c|c|c|c|}
\hline Test allergen & Allergen manufacturer & Authorization No & Date of Authorization \\
\hline Locust Tree & Allergopharma GmbH \& Co. KG & $398 a / 86 b$ & 04.06.1991 \\
\hline Trees I (early sporulation) & Allergopharma GmbH \& Co. KG & $416 a / 86 b$ & 04.06.1991 \\
\hline Trees II (intermediate sporulation) & Allergopharma GmbH \& Co. KG & $417 a / 86 b$ & 04.06.1991 \\
\hline Birch & HAL Allergie GmbH & $1321 \mathrm{a} / 89 \mathrm{Nb}-1$ & 01.04 .1990 \\
\hline Birch & Allergopharma GmbH \& Co. KG & $388 a / 86 b$ & 04.06.1991 \\
\hline Birch & Leti Pharma GmbH & PEI.D.02356.01.2 & 07.04 .2003 \\
\hline Beech & HAL Allergie GmbH & 1326a/89Nb-1 & 01.04 .1990 \\
\hline European beech & Allergopharma GmbH \& Co. KG & $399 a / 86 b$ & 04.06.1991 \\
\hline Oak & HAL Allergie GmbH & 1324a/89Nb-1 & 01.04 .1990 \\
\hline Oak & Allergopharma GmbH \& Co. KG & $401 a / 86 b$ & 04.06 .1991 \\
\hline Alder & HAL Allergie GmbH & 1323a/89Nb-1 & 01.04 .1990 \\
\hline Alder & Allergopharma GmbH \& Co. KG & $402 a / 86 b$ & 04.06.1991 \\
\hline Ash & HAL Allergie GmbH & $1325 \mathrm{a} / 89 \mathrm{Nb}-1$ & 01.04 .1990 \\
\hline Ash & Allergopharma GmbH \& Co. KG & $403 a / 86 b$ & 04.06.1991 \\
\hline Early flowering Tree-mix I & HAL Allergie GmbH & 1338a/89Nb-1 & 01.04 .1990 \\
\hline Hazel & HAL Allergie GmbH & 1320a/89Nb-1 & 01.04 .1990 \\
\hline Hazel & Allergopharma GmbH \& Co. KG & $406 a / 86 b$ & 04.06.1991 \\
\hline Lime tree & Allergopharma GmbH \& Co. KG & $411 a / 86 b$ & 04.06.1991 \\
\hline Cottonwood & HAL Allergie GmbH & 1327a/89Nb-1 & 01.04 .1990 \\
\hline Cottonwood & Allergopharma GmbH \& Co. KG & $412 a / 86 b$ & 04.06.1991 \\
\hline Planetree & Allergopharma GmbH \& Co. KG & $413 a / 86 b$ & 04.06.1991 \\
\hline Elm & Allergopharma GmbH \& Co. KG & $414 a / 86 b$ & 04.06 .1991 \\
\hline Pasture & HAL Allergie GmbH & $1322 \mathrm{a} / 89 \mathrm{Nb}-1$ & 01.04 .1990 \\
\hline Pasture & Allergopharma GmbH \& Co. KG & $415 a / 86 b$ & 04.06.1991 \\
\hline
\end{tabular}

allergen extracts in the future ${ }^{(12)}$. The CREATE project (Development of Certified Reference Materials for Allergen Products and Validation of Methods for Their Quantification), a program funded by the European Union (EU) under the fifth framework program in the field of allergen standardization ${ }^{(22)}$ aimed at developing certified reference materials for allergen products based on purified recombinant allergens ${ }^{(12)}$. These allergens should serve as standards for the calibration of in vitro allergen quantification assays. These assays could then be applied to allergen products and would permit an uniform quantification of the major allergens contained in the products in mass units ${ }^{(12)}$. This way of standardization would allow for comparability of allergen products from different manufacturers. Two recombinant major allergens, rBet $v 1$ and $\mathrm{rPhl}$ p5a were found to be suitable as reference materials in a follow-up project to CREATE ${ }^{(12)}$. The respective ELISAs were also validated, therefore, these two allergens should be established as biological reference preparations and the respective ELISAs as EP standard methods ${ }^{(23)}$.

Regulatory requirements for a Marketing Authorization Ap- 
Table 1. Moulds.

\begin{tabular}{|c|c|c|c|}
\hline Test allergen & Allergen manufacturer & Authorization No & Date of Authorization \\
\hline Alternaria alternata & Leti Pharma GmbH & PEI.D.02949.01.2 & 18.03.2004 \\
\hline Alternaria alternata & HAL Allergie GmbH & 1356a/89Nb-2 & 01.04 .1990 \\
\hline Alternaria tenuis (A. alternata) & Allergopharma GmbH \& Co. KG & $328 a / 87 b$ & 04.06 .1991 \\
\hline Aspergillus fumigatus & Allergopharma GmbH \& Co. KG & $351 a / 87 b$ & 04.06 .1991 \\
\hline Aspergillus fumigatus & HAL Allergie GmbH & $1357 \mathrm{a} / 89 \mathrm{Nb}-2$ & 01.04 .1990 \\
\hline Botrytis cinerea & Allergopharma GmbH \& Co. KG & $352 a / 87 b$ & 04.06.1991 \\
\hline Candida albicans & HAL Allergie GmbH & $1364 \mathrm{a} / 89 \mathrm{Nb}-2$ & 01.04.1990 \\
\hline Cladosporium cladosporioides & HAL Allergie GmbH & $1367 \mathrm{a} / 89 \mathrm{Nb}-2$ & 01.04 .1990 \\
\hline Cladosporium herbarum & Allergopharma GmbH \& Co. KG & $355 a / 87 b$ & 04.06 .1991 \\
\hline Cladosporium herbarum & Leti Pharma GmbH & PEI.D.02997.01.2 & 24.04 .2007 \\
\hline Curvularia lunata & Allergopharma GmbH \& Co. KG & $356 a / 87 b$ & 04.06.1991 \\
\hline Fusarium moniliforme & Allergopharma GmbH \& Co. KG & $357 a / 87 b$ & 04.06 .1991 \\
\hline Helminthosporium halodes & Allergopharma GmbH \& Co. KG & $358 a / 87 b$ & 04.06 .1991 \\
\hline Mucor mucedo & HAL Allergie GmbH & 1372a/89Nb-2 & 01.04 .1990 \\
\hline Mucor mucedo & Allergopharma GmbH \& Co. KG & $360 a / 87 b$ & 04.06 .1991 \\
\hline Penicillium notatum & Allergopharma GmbH \& Co. KG & $362 a / 87 b$ & 04.06.1991 \\
\hline Pullularia pullulans & Allergopharma GmbH \& Co. KG & $364 a / 87 b$ & 04.06.1991 \\
\hline Rhizopus nigricans & Allergopharma GmbH \& Co. KG & $365 a / 87 b$ & 04.06 .1991 \\
\hline Mould and Yeasts mix B PC & HAL Allergie GmbH & 1392a/89Nb-1 & 01.04.1990 \\
\hline Mould and Yeasts mix B SP & HAL Allergie GmbH & $1392 \mathrm{a} / 89 \mathrm{Nb}-2$ & 01.04 .1990 \\
\hline $\begin{array}{l}\text { Serpula lacrymans (Merulius } \\
\text { lacrymans) }\end{array}$ & Allergopharma GmbH \& Co. KG & $367 a / 87 b$ & 04.06 .1991 \\
\hline
\end{tabular}

\section{plication for NPT test allergens}

The regulation of TAs follows the European Pharmacopoeia and the European Medicines Agency (EMA) Guideline on allergen products ${ }^{(11,14,16,24)}$.

For authorization of a TA, several regulatory requirements have to be fulfilled like clinical trials, regular update of the dossiers, handling of variation processes, ongoing stability testing and creation of periodic safety update reports (PSURs).

According to the Guideline on Clinical Evaluation of Diagnostic Agents ${ }^{(25)}$, clinical trials for test allergens have to be carried out before application for a MA is possible. Thereby, the manufacturer is expected to demonstrate safety, sensitivity and specificity of the TA.

Such studies are time consuming since planning, implementati- on and evaluation may take several years and induce high costs. Additional expenses arise from the development of appropriate methods for quality assurance and the requirements of stability studies. The permitted potency variation of the labelled activity is $50 \%$ to $150 \%$ in the EMA 2010 guideline version being $50 \%$ to $200 \%$ in the earlier monograph ${ }^{(25)}$. Moreover, for products without potency measurements which are defined on protein content only, the permitted variation is $80 \%$ to $120 \%$ of the labelled amount. According to the guidelines on Good Manufacturing Practice (GMP), stability studies need to be performed that include the continuous determination of the activity of the active substance of at least 3 batches of a TA covering the product's whole shelf life period.

A decentralized procedure for new marketing authorizations 
Table 1. House Dust Mites / Storage Mites.

\begin{tabular}{|c|c|c|c|}
\hline Test allergen & Allergen manufacturer & Authorization No & Date of Authorization \\
\hline Acarus siro & Allergopharma GmbH \& Co. KG & $1863 a / 89 a$ & 04.06.1991 \\
\hline Dermatophagoides farinae & Leti Pharma GmbH & PEI.D.01596.01.2 & 17.12.2002 \\
\hline Dermatophagoides farinae & Allergopharma GmbH \& Co. KG & $467 a / 87 b$ & 04.06.1991 \\
\hline Dermatophagoides pteronyssinus & Leti Pharma GmbH & PEI.D.01598.01.2 & 17.12.2002 \\
\hline Dermatophagoides pteronyssinus & Allergopharma GmbH \& Co. KG & $466 a / 87 b$ & 04.06.1991 \\
\hline Dust mite I (D-pter-) & HAL Allergie GmbH & $1403 \mathrm{a} / 89 \mathrm{Nb}-2$ & 01.04 .1990 \\
\hline Dust mite II (D-farinae) & HAL Allergie GmbH & $1404 \mathrm{a} / 89 \mathrm{Nb}-2$ & 01.04 .1990 \\
\hline Lepidoglyphus destructor & Allergopharma GmbH \& Co. KG & $1864 a / 89 a$ & 04.06.1991 \\
\hline Tyrophagus putrescentiae & Allergopharma GmbH \& Co. KG & $1865 a / 89 a$ & 04.06.1991 \\
\hline
\end{tabular}

Table 1. Animal dander / epithelia.

\begin{tabular}{|c|c|c|c|}
\hline Test allergen & Allergen manufacturer & Authorization No & Date of Authorization \\
\hline Hamster & Allergopharma GmbH \& Co. KG & $25 a / 87 b$ & 04.06.1991 \\
\hline Dog & Allergopharma GmbH \& Co. KG & $27 a / 87 b$ & 04.06.1991 \\
\hline Dog & HAL Allergie GmbH & $1436 \mathrm{a} / 89 \mathrm{Nb}$ & 01.04 .1990 \\
\hline Rabbit & Allergopharma GmbH \& Co. KG & $29 a / 87 b$ & 04.06.1991 \\
\hline Cat & Leti Pharma GmbH & PEI.D.02762.01.2 & 17.06.2003 \\
\hline Cat & HAL Allergie $\mathrm{GmbH}$ & $1437 \mathrm{a} / 89 \mathrm{Nb}$ & 01.04.1990 \\
\hline Cat & Allergopharma GmbH \& Co. KG & $389 a / 86 b$ & 04.06.1991 \\
\hline Cow & HAL Allergie GmbH & $1438 \mathrm{a} / 89 \mathrm{Nb}$ & 01.04.1990 \\
\hline Guinea pig & Allergopharma GmbH \& Co. KG & $31 a / 87 b$ & 04.06.1991 \\
\hline Horse & Allergopharma GmbH \& Co. KG & $32 a / 87 b$ & 04.06 .1991 \\
\hline Horse & HAL Allergie GmbH & $1439 a / 89 \mathrm{Nb}$ & 01.04.1990 \\
\hline Bovine & Allergopharma GmbH \& Co. KG & $34 a / 87 b$ & 04.06.1991 \\
\hline
\end{tabular}

where a product can be authorized directly in different member states is possible in addition. This procedure is of equal effort than the authorization of a new therapeutic allergen product. After MA, the entire approval documentation must be kept up to date in every country in which the TA is authorized ${ }^{(11)}$ including documentation of adverse events collected during routine use in the market, from clinical trials and from publications in PSURs. PSURs should allow the authority to evaluate the risk-benefit potential of the drug ${ }^{(25)}$. During the first 2 years after approval for a TA, these have to be submitted to the national authority every 6 months, in year 3 and 4 every 12 months and thereafter every 3 years.

\section{What will happen to NPT allergen extracts for routine use in the EU?}

Since the financial expenses for initiation and maintenance of NPT allergen product authorizations far outreach possibly related revenues, the manufacturers may be forced to significantly limit their allergen portfolios. Significant price increases can be anticipated for the remaining TAs. Most of the expenditures are 
Table 2. Important National laws, directives, decrees and registries regulating allergens for provocation testing in Europe

\begin{tabular}{|c|c|}
\hline State & National laws, directives, decrees \\
\hline Germany & $\begin{array}{l}\text { German national Drug Law and Pharmaceutical } \\
\text { Products and Active Ingredients Manufacturing } \\
\text { Regulation }\end{array}$ \\
\hline United Kingdom & $\begin{array}{l}\text { British Pharmaceutical Products law and British } \\
\text { Pharmacopeia }\end{array}$ \\
\hline Spain & $\begin{array}{l}\text { Royal Decree covering among other items the } \\
\text { registration of allergen products ( } 10.2013 \text { vom } 24 \text {. } \\
\text { 07. 2013) }\end{array}$ \\
\hline Austria & $\begin{array}{l}\text { Austrian Registry of pharmaceutical specialty pro- } \\
\text { ducts, allergen manufacturing regulations, } \S 7 a\end{array}$ \\
\hline The Netherlands & Geneesmiddelenwet, Dutch national drug law \\
\hline Sweden & National Guidelines: LVFS 2003:11 and 2014:7 \\
\hline Czech Republic & $\begin{array}{l}\text { National Drug Law: Act No. 378/2007 Coll. of } 06 . \\
\text { 12. } 2007\end{array}$ \\
\hline Switzerland & $\begin{array}{l}\text { Swiss Drug law, abbreviated procedure for allergen } \\
\text { products that are already registered in other } \\
\text { countries. }\end{array}$ \\
\hline
\end{tabular}

fix costs independent of the quantity sold. Thus, prices for invivo allergen products used in lower quantities like NPT TAs may need to be twenty to fifty fold higher than prices of frequently used Prick test TAs ${ }^{(11)}$.

Thus, several NPT allergen products will disappear from the market and it is of little probability that manufacturers will apply for more than a limited low number of new MAs.

\section{Discussion}

NPT depends on the quality of the allergen extract used for the provocation. Until now, not all commercial allergen extracts fullfil the required quality standards (26). In addition to standardization, the stability and purity of allergen extracts needs to be controlled ${ }^{(27)}$ and preservatives in the extract may induce nonspecific nasal reactions. This explains why registration and authorization of NPT-TAs by national authorities within the EU with quality control of all parameters listed above is of special importance for patients and allergologists.

In routine use, the nasal allergen provocation model uses either a single (supra-threshold) provocation or a series of successive provocations of increasing allergen dose separated by at least 10 minute intervals (titrated provocation) ${ }^{(28-32)}$. Whereas the first method is used for diagnostic purposes and allows a qualitative evaluation, the latter is suited to get a more quantitative information on the sensitivity of the mucosa and thus allows for evaluations of all kinds of treatments of allergic rhinitis ${ }^{(28-32)}$. According to the Europan Medical Agency (EMA), NPT can be used in phase-II-studies to evaluate the dose-response effects of allergen immunotherapy (AIT) ${ }^{(33)}$. It has been used in several controlled clinical trials ${ }^{(34-39)}$. Moreover, it has been recommended for evaluations of the efficacy of AIT in routine every-day use ${ }^{(40)}$. In this regard, NPT should be performed in a titrated manner to assess changes in the individual nasal threshold dose. A titrated NPT allows comparisons of the pre- and posttreatment nasal allergen thresholds. Target parameter in the first approach is the quantitiy of the clinical response of the mucosa measured using symptom scoring, rhinomanometry or acoustic rhinometry measures or biomarkers in nasal secretions (29), the target parameter in the second approach is the allergen dose that provokes the predefined threshold response. If employed in this way, NPT may detect even small differences between treatments in comparatively low numbers of subjects ${ }^{(41)}$. NPT might also generate useful information in the evaluation of asthmatic patients, since $85 \%$ of patients show identical responses at the nasal and bronchial mucosa upon allergen challenges, however NPT is a much safer procedure compared to allergenspecific bronchial provocation ${ }^{(42,43)}$. This co-dependence is given in $90 \%$ of grass pollen allergics, but only in $70 \%$ of house dust mite allergics ${ }^{(42,43)}$. In asthmatic children, NPT with aeroallergens was found to be useful in establishing the clinically relevant allergen and to be safe even in the absence of rhinitis ${ }^{(44)}$. Moreover, NPT might be especially useful in a subgroup of patients with symptoms of $\mathrm{AR}$, demonstrating an IgE-production at the site of the nasal mucosa without detection of a systemic allergic sensitization in skin-tests or in serum. This phenomenon represents the so called "local allergic rhinitis (LAR)" (6,7,45,46). Evidence exists for a specific Th2-cytokine release and Tryptaseand Eosinophil Cationic Protein-production in the nasal mucosa after allergen exposure in these patients without systemic sensitization. It could be demonstrated that these patients also have an early and/or late-phase response to NPT (7). LAR can be diagnosed using a single NPT test extract even if patients suffer from a clinically relevant polysensitization to different aeroallergens (46). However, the multiple aeroallergen extracts that are needed to perform such NPT's may no longer be available. Each individual mixture of different allergen extracts will create a new allergen product and each thus created NPT allergen product will require a new application for a MA.

\section{Conclusion}

In conclusion, the regulatory requirements for legislation within the EU have a tremendous impact on the availability of diagnostic allergens for NPT in Europe and will make make nasal provo- 
cation testing allergens unavailable in different member states.

\section{Acknowledgements}

This study was support partially by the European Rhinologic Society - Clinical Research Grant 2013- in cooperation with the Foundation of Rhinology and Facial Surgery (RHiPla-Stifung Ulm, Germany).

\section{Author contributions}

According to ICMJE recommendations, all authors (LK, $\mathrm{AH}, \mathrm{PH}$, $W F, H J H, A M, N P$ ) have fullfilled all of the following criteria: sub- stantial contributions to the conception of the paper, interpretation of data, revising it critically, finally approving the version to be published and agreeing to be accountable for all aspects of the work in ensuring that questions related to the accuracy or integrity of any part of the work are appropriately investigated and resolved. In addition, LK has drafted the conception of the study, was responsible for data aquisition, has written the first version of the manuscript and served as corresponding author.

\section{Conflict of interest}

No conflict of interest.

\section{References}

1. Halpern SR, Holman J, Whittaker C. The correlation between skin and respiratory mucous membrane tests with molds in allergic rhinitis. Ann Allergy. 1961; 19: 14071414

2. Blackley C. Experimental researches on the cause and nature of catarrhus aestivus (hay fever of hay asthma). Daxson's of Pall Mall. 1873

3. Heppt W, Bachert C. Praktische Allergologie Stuttgart: Georg Thieme Verlag; 2011(2)

4. Saloga J, Klimek L, Buhl R, Mann W, Knop J. Allergologie-Handbuch: Grundlagen und klinische Praxis. Stuttgart: Schattauer Verlag; 2011.

5. Cazan D, Hackenberg B, Pfaar O, Klimek L. Die nasale Provokationstestung mit Allergenen. Methoden der klinischen Anwendung. Allergo J. 2013; 22: 189-200.

6. Rondon C, Campo P, Togias A, Fokkens WJ, Durham SR, Powe DG, et al. Local allergic rhinitis: concept, pathophysiology, and management. J Allergy Clin Immunol. 2012; 129: 1460-1467

7. Lopez S, Rondon C, Torres MJ, Campo P, Canto G, Fernandez R, et al. Immediate and dual response to nasal challenge with Dermatophagoides pteronyssinus in local allergic rhinitis. Clin Exp Allergy. 2010; 40: 1007-1014.

8. Albegger K. [Diagnosis of allergic rhinitis. I. Anamnesis--ENT medical examination--skin tests--intranasal provocation]. Hno. 1991; 39: 77-81

9. Bachert C. [Reproducibility of the intranasal provocation test]. Laryngologie, Rhinologie, Otologie. 1987; 66: 157-160.

10. EU Council Directive $89 / 342 /$ EEC of 3 May 1989 extending the scope of Directives 65/65/EEC and 75/319/EEC and laying down additional provisions for immunological medicinal products consisting of vaccines, toxins or serums and allergens. Official Journal L. 1989; 142 (25/05/1989): 0014-0015

11. Klimek L. Zulassungen von Testallergenen: Diagnostika in Not. Allergo J. 2013; 22 (7). 522.

12. Limpert AS. Quality of Allergen Products for Specific Immunotherapy - A Guidance for Industry for Compilation of Module 3 for the EU CTD (Quality), considering the German Therapy Allergen Ordinance, the revised European Pharmacopoeia Monograph on Allergen Products (2010:1063) and the new "Guideline on Allergen Products - Production and Quality Issues" University of Bonn, Germany; 2010.

13. 2001 CDEo. http://ec.europa.eu/enterprise/pharmaceuticals/eudralex/vol-1/ dir_2001_83/dir_2001_83_de.pdf. In: 2001 OJotEULD, editor. 2001.

14. Guideline on allergen products: production and quality issues. 2008. London, European Medicines Agency (EMEA), (2009).

15. Nelson HS. Allergen immunotherapy: where is it now? J Allergy Clin Immunol. 2007; 119: 769-779.

16. (EDQM) EDftQoM. Monograph: Allergen Products - Producta Allergenica 01/2010:1063. In: Pharmacopoeia E, editor: Council of Europe; 2010. p. 679-680.

17. Guideline on Allergen Products: Production and Quality Issues.

18. Larsen JN, Houghton CG. Manufacturing and standardizing Allergen Extracts in Europe. Allergens and Allergen Immunotherapy. 4th Edition: Informa Healthcare New York, USA; 2008.

19. Turkeltaub PC. Biological standardization of allergenic extracts. Allergol Immunopathol (Madr). 1989; 17: 53-65.

20. Medicines NCo. Registration of Allergenic Preparations. Nordic Guidelines. Uppsala, Sweden: NLN Publications; 1989

21. Reuter A, Luttkopf D, Vieths S. New frontiers in allergen standardization. Clin Exp Allergy. 2009; 39: 307-309.

22. van Ree $R$, Chapman MD, Ferreira F, Vieths S, Bryan D, Cromwell O, et al. The CREATE project: development of certified reference materials for allergenic products and validation of methods for their quantification. Allergy. 2008; 63: 310-326.

23. Neske F, Schorner C, Buchheit KH, Costanzo A, Hanschmann KM, Himly M, et al. BSP090-the follow-up to CREATE. Arb Paul Ehrlich Inst Bundesinstitut Impfstoffe Biomed Arzneim Langen Hess. 2009;96: 12-20.

24. de Blay F, Doyen V, Bloch-Morot E, Caillot D, Gayraud J, de Laval A, et al. French applica- tion of the European guidelines for regulation of allergenic extracts. J Allergy Clin Immunol. 2013; 131: 1435-1437.

25. European Medicines Agency. Guideline on clinical evaluation of diagnostic agents. 2010.

26. Demoly P, Campbell A, Lebel B, Bousquet J. Experimental models in rhinitis. Clin Exp Allergy. 1999; 29 Suppl 3: 72-76.

27. Andersson M, Greiff $L$, Svensson C, Persson C. Various methods for testing nasal responses in vivo: a critical review. Acta Otolaryngol. 1995; 115: 705-713.

28. Klimek L, Bergmann KC, Walliczek U, Pfaar O. Verfahren zur klinischen Beurteilung der Wirksamkeit einer allergenspezifischen Immuntherapie: Aktuelle Trends und Neue Entwicklungen. Allergologie. 2013; Jahrgang 36: 267-274.

29. Klimek $L$, Wolf $H$, Mewes $T$, Dormann D, Reske-Kunz A, Schnitker J, et al. The effect of short-term immunotherapy with molecular standardized grass and rye allergens on eosinophil cationic protein and tryptase in nasal secretions. J Allergy Clin Immunol. 1999; 103: 47-53.

30. Klimek L, Dormann D, Jarman ER, Cromwell $\mathrm{O}$, Riechelmann H, Reske-Kunz AB. Shortterm preseasonal birch pollen allergoid immunotherapy influences symptoms, specific nasal provocation and cytokine levels in nasal secretions, but not peripheral T-cell responses, in patients with allergic rhinitis. Clin Exp Allergy. 1999; 29: 1326-1335.

31. Pfaar O, Anders C, Klimek L. Clinical outcome measures of specific immunotherapy. Curr Opin Allergy Clin Immunol. 2009; 9: 208-213.

32. Pfaar O, Kleine-Tebbe J, Hormann K, Klimek L. Allergen-specific immunotherapy: which outcome measures are useful in monitoring clinical trials? Immunol Allergy Clin North Am. 2011; 31: 289-309.

33. Guideline on the clinical development of products for specific immunotherapy. (24 May 2007).

34. Creticos PS, Schroeder JT, Hamilton RG, Balcer-Whaley SL, Khattignavong AP, Lindblad R, et al. Immunotherapy with a ragweed-toll-like receptor 9 agonist vaccine for allergic rhinitis. N Engl J Med. 2006; 355: 
1445-1455

35. Purohit $A$, Niederberger $V$, Kronqvist $M$, Horak F, Gronneberg R, Suck R, et al. Clinical effects of immunotherapy with genetically modified recombinant birch pollen Bet $v 1$ derivatives. Clin Exp Allergy. 2008; 38: 15141525.

36. Keskin O, Tuncer A, Adalioglu G, Sekerel BE, Sackesen C, Kalayci O. The effects of grass pollen allergoid immunotherapy on clinical and immunological parameters in children with allergic rhinitis. Pediatr Allergy Immunol. 2006; 17: 396-407.

37. Tahamiler R, Saritzali G, Canakcioglu S. Long-term efficacy of sublingual immunotherapy in patients with perennial rhinitis Laryngoscope. 2007; 117: 965-969.

38. Pfaar O, Barth C, Jaschke C, Hormann K, Klimek L. Sublingual allergen-specific immunotherapy adjuvanted with monophosphoryl lipid A: a phase I/lla study. Int Arch Allergy Immunol. 2011; 154: 336344.

39. Klimek L, Schendzielorz P, Pinol R, Pfaar O Specific subcutaneous immunotherapy with recombinant grass pollen allergens: first randomized dose-ranging safety study. Clin Exp Allergy. 2012; 42: 936-945.

40. Klimek L, Reske-Kunz A, Malling HJ. Beurteilung des Therapieerfolges einer Immuntherapie. In: Klimek L, ReskeKunz A, Saloga J, editors. Spezifische Immuntherapie, Hyposensibilisierung. Stuttgart: Thieme Verlag; 1999.

41. Deruaz C, Leimgruber $A$, Berney $M$, Pradervand E, Spertini F. Levocetirizine better protects than desloratadine in a nasal provocation with allergen. J Allergy Clin Immunol. 2004; 113: 669-676.

42. Cazan D, Hackenberg B, Pfaar O, Klimek L. Die nasale Provokationstestung mit Allergenen. Methoden der klinischen Anwendung. Allergo J. 2013; 22: 189-200.

43. Saloga J, Klimek L, Buhl R, Knop J Allergologie-Handbuch: Grundlagen und klinische Praxis 2011 (2).

44. Hervas D, Rodriguez R, Garde J. Role of aeroallergen nasal challenge in asthmatic children. Allergol Immunopathol (Madr). 2011; 39: 17-22.

45. Klimek L, von Bernus L, Pfaar O. [Local (exclusive) IgE production in the nasal mucosa. Evidence for local allergic rhinitis]. Hno. 2013; 61: 217-323.

46. Rondon C, Campo P, Herrera R, BlancaLopez N, Melendez L, Canto G, et al. Nasal allergen provocation test with multiple aeroallergens detects polysensitization in local allergic rhinitis. J Allergy Clin Immunol. 2011; 128: 1192-1197.

Prof. Dr. med. Ludger Klimek Center for Allergy and Rhinology

An den Quellen 10

D-65183 Wiesbaden

Germany

Tel.: +49-611-308 6080

E-mail: Ludger.Klimek@Allergiezen-

trum.org 